\title{
Explorando el cuarto poder en el mundo de las viñetas
}

Reseña de: Matos Agudo, D., Periodismo Cómic. Una historia del género desde los pioneros a Joe Sacco, Salamanca, Comunicación Social.

Ediciones y publicaciones, 2017

Carlos J. Eguren Hernández

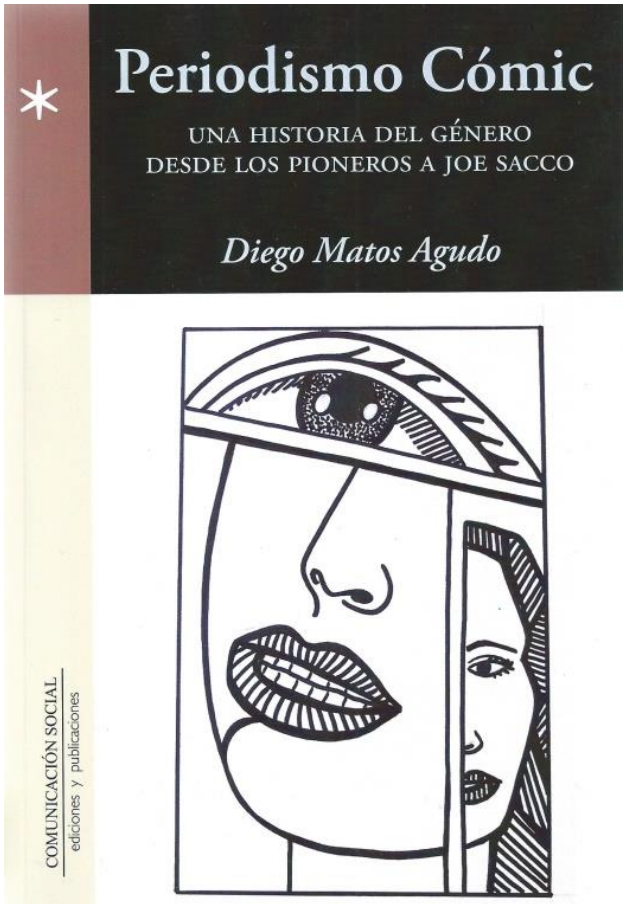

¿Qué es el periodismo cómic? ¿Existe en realidad un modo de contar historias reales a través de los tebeos? ¿Puede ser un nuevo género o un híbrido dentro del campo de la comunicación? Preguntas interesantes que se formulan por fin en una obra teórica pionera como es Periodismo Cómic. Una historia del género desde los pioneros a Joe Sacco.

En esta época donde la crisis de los medios de comunicación tradicional parece nunca terminar (como si siempre hubiese estado ahí) y se persigue, se busca, la constante reinvención que ofrecen otros medios en

Internet, el periodismo cómic se vislumbra como un nuevo modo de narrar, de contar la verdad, de informar, de ser honestos con aquello que nos rodea, mezclando el impacto informativo y el artístico. Basta con centrarse en diferentes obras de esta índole firmadas por Joe Sacco o en la web informativa que utiliza el cómic como herramienta, Pictoline, para percatarnos de cómo una pequeña revolución se ha iniciado dentro del cómic y la comunicación.

Pero ¿de dónde surge el periodismo cómic? Antes debemos vincular el nacimiento de las viñetas dentro de los periódicos. Nos remontamos, con el texto de Matos, al éxito de las primeras grandes tiras cómicas que dieron 
calificativo al periodismo amarillista. Esta es una expresión o un nombre que hoy damos por hecho, pero si nos volvemos a su origen, procede de la disputa de Randolph Hearst y Joseph Pulitzer para lograr para sus periódicos las exitosas viñetas de Mickey Dugan o The Yellow Kid de Richard Felton Outcault. Es interesante, por tanto, centrarnos en cómo el mundo del cómic ha surgido y tomado forma a partir de estas viñetas cómicas, convirtiéndose ahora en el noveno arte, un universo donde todo es posible.

Desde este punto, el periodista y doctor en Comunicación por la Universidad Pontificia de Salamanca, Diego Matos Agudo, nos presenta un análisis del modo en el que el cómic ha aparecido en las páginas de la prensa y cómo la prensa ha emergido en las viñetas de los tebeos, a lo largo de un libro que mezcla el fervor académico y el del aficionado al noveno arte. No hablamos de una simple conversión de un medio periodístico al cómic, sino de una forma propia de contar.

El periodismo de cómic es un periodismo de fondo, que lucha contra la inmediatez informativa, contra las prisas del cierre en las redacciones y contra el consumo masivo de noticias. [...] Una obra de cómic periodístico se degusta con calma, desde la aparente ficción del material obtenido de las fuentes, se aprecia en conjunto, se interioriza, se sufre al detalle. ${ }^{1}$

Autor de varios libros dedicados a series y cómics como The Walking Dead y a proyectos sobre películas retro en Back to culture, Matos recorre aquí diferentes aspectos, desde el surgimiento de las viñetas periodísticas hasta la aparición de varios periodistas en el mundo del cómic, llegando a auténticas crónicas narradas en este formato.

¿No es acaso Clark Kent, el otro yo de Superman, un periodista? Y es en el espacio reservado a los periodísticas cómiqueros donde Matos habla también sobre el Tintín en la célebre serie homónima de Hergé o el combativo Ben Urich o el polémico editor J. J. Jameson de Marvel Cómics. A través de este último campo, se recogen títulos recientes como The Private Eye, donde se otorga un enfoque distópico a los medios de comunicación gracias al trabajo del guionista Brian K. Vaughan y el dibujante Marcos Martín:

1 Matos Agudo, D., Periodismo Cómic. Una historia del género desde los pioneros a Joe Sacco, Salamanca, Comunicación Social. Ediciones y publicaciones, 2017, p. 152. 
En esta serie futurista distópica, nadie es quien dice ser, todos se esconden tras unas máscaras porque una noche hubo un diluvio de información y todo lo que había en la red se desveló hacia todos. Ya nadie tenía secretos. Todo era de dominio público. Ahora, en el año 2076, Internet ha desaparecido, no existe policía, sino que los guardianes del orden público son periodistas, la Prensa. Y no hay detectives privados, hay paparazzis. ${ }^{2}$

Dejando de lado la distopía del futuro ficcional, Periodismo Cómic. Una historia del género desde los pioneros a Joe Sacco avanza por los diferentes campos de la comunicación y por los distintos terrenos del cómic, donde se habla de los superhéroes, pero también del cómic contracultural (o underground) que toma las vidas de personas de a pie, más allá de vigilantes enmascarados. Es ahí donde se encuentran interesantes reflexiones sobre la cabida de este modo de contar historias que trasciende o dan nueva forma al periodismo más clásico con autores como Paco Roca o Rayco Pulido, entre otros, como exponentes.

Más allá de este epígrafe, en sus páginas hay espacio para los cómics autobiográficos de Harvey Pekar y su American Splendor pasando por fieles retratos de la sociedad como El contrato con Dios de Will Eisner, famoso creador de The Spirit. A su vez, el Nuevo Periodismo ocupa varias páginas donde se discierne cómo este utilizó algunas formas del cómic (por ejemplo, las onomatopeyas) o cómo el cómic halló nuevas fórmulas para contar sus historias a través de las técnicas utilizadas por autores como Tom Wolfe.

La crónica y el reportaje son dos géneros periodísticos que funcionan en el Nuevo Periodismo y también lo hacen en el periodismo cómic, donde hay ejemplos como Joe Sacco. Es en la biografía de este autor alternativo estadounidense donde Matos profundiza, desde sus inicios como ilustrador de la obra de Pekar, para luego dar el salto a obras donde se refleja el sufrimiento causado por la guerra o historias políticas. Algunos ejemplos de ellas serían Notas al pie de Gaza o Días de destrucción, días de revuelta. Matos señala varios de estos puntos sobre cómo la documentación, las vivencias, las crónicas, el documental... se arrojan en todo momento en las viñetas de Sacco, todo un ejemplo del periodismo cómic. Y es que Matos cataloga a Sacco de paradigma y, continuando con la trayectoria del autor nacido en Malta, es una cuestión casi indudable.

2 Ibidem, p. 56. 
Al igual que señala en su prólogo Antonio López Hidalgo, en Periodismo Cómic se explora un nuevo y respetable género que brota del periodismo transmediático. En esta época multimedia e hipertextual, el arte del periodismo utiliza nuevas herramientas como el cómic. Como indica Matos, su libro busca demostrar que el cómic periodismo no «se trata de un formato más en el que publicar reportajes, entrevistas o crónicas, sino que tenía entidad propia, como género periodístico de primer orden, en el que publicar piezas informativas de gran calado». ${ }^{3}$ Es un libro que sirve de guía para futuros trabajos académicos, pero también para lectores que quieran descubrir nuevas obras donde el periodismo y el cómic se fusionan. No cabe duda al lector que se sumerge con profundidad en esta obra que el propósito de su autor se cumple, ya sea por medio de la investigación o la reflexión, con multitud de fuentes que enriquecen un colosal esfuerzo para abrir una nueva senda dentro de los estudios del periodismo y el cómic. 